\title{
Eating breakfast together as a family: mealtime experiences and associations with dietary intake among adolescents in rural Minnesota, USA
}

\author{
Nicole Larson ${ }^{1, *}$, Qi Wang ${ }^{2}$, Jerica M Berge ${ }^{3}$, Amy Shanafelt ${ }^{3}$ and Marilyn S Nanney ${ }^{3}$ \\ 'Division of Epidemiology and Community Health, School of Public Health, University of Minnesota, 1300 South Second \\ Street, Suite 300, Minneapolis, MN 55454, USA: ${ }^{2}$ Biostatistical Design and Analysis Center, Clinical and Translational \\ Science Institute, University of Minnesota, Minneapolis, MN, USA: ${ }^{3}$ Department of Family Medicine \& Community \\ Health, Program in Health Disparities Research, University of Minnesota, Minneapolis, MN, USA
}

Submitted 22 0ctober 2015: Final revision received 25 January 2016: Accepted 8 February 2016: First published online 14 March 2016

\begin{abstract}
Objective: Although existing evidence links breakfast frequency to better dietary quality, little is known specifically in regard to the benefits associated with eating breakfast together with one's family. The present study describes the prevalence and experience of having family meals at breakfast among rural families and examines associations between meal frequency and adolescent diet quality. Design: Data were drawn from Project BreakFAST, a group-randomized trial aimed at increasing school breakfast participation in rural Minnesota high schools, USA. Linear mixed models were used to examine associations between student reports of family breakfast frequency and Healthy Eating Index 2010 (HEI-2010) scores while accounting for clustering within schools, demographics and household food security.

Setting: Adolescent students from sixteen schools completed online surveys, height and weight measurements, and dietary recalls at baseline in 2012-2014.

Subjects: The sample included 827 adolescents ( $55 \cdot 1 \%$ girls) in grades 9-10 who reported eating breakfast on at most three days per school week.

Results: On average, adolescents reported eating breakfast with their family 1.3 (SD 1.9) times in the past week. Family breakfast meals occurred most frequently in the homes of adolescents who reported a race other than white $(P=0.002)$ or Hispanic ethnicity $(P=0 \cdot 02)$. Family breakfast frequency was directly associated with adolescent involvement in preparing breakfast meals $(P<0 \cdot 001)$ and positive attitudes $(P \leq 0 \cdot 01)$ about mealtime importance, interactions and structure. Family breakfast frequency was unrelated to most diet quality markers.

Conclusions: Family meals may be one important context of opportunity for promoting healthy food patterns at breakfast. Additional research is needed to better inform and evaluate strategies.
\end{abstract}

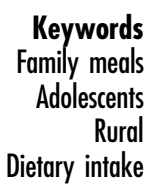

Several studies have demonstrated that adolescents who have more family meals each week, and particularly more frequent family meals in the evening, have diets of higher nutritional quality as distinguished by higher intakes of fruit, vegetables and key nutrients (e.g. fibre, $\mathrm{Ca}, \mathrm{Fe}$ and several vitamins) and lower intakes of sugar-sweetened drinks and saturated fat ${ }^{(1-6)}$. Based on this research, efforts to promote the practice of eating together have increased over the past decade along with attention to the barriers experienced by families. Particularly common barriers experienced by US families include different schedules and difficulty finding time to eat together ${ }^{(7,8)}$. For example, one study involving 902 parents of adolescents found that
$79 \%$ of parents and $54 \%$ of adolescents reported having different schedules that made it challenging to eat together $^{(8)}$. It is therefore important that public health messages and interventions designed to promote family meals are informed by research regarding whether it matters if families eat together in the evening $v$. other times of the day.

Although there is also substantial evidence that links frequency of eating breakfast to diets of overall better nutritional quality ${ }^{(9)}$, little is known about the prevalence and benefits associated with eating breakfast together with one's family. Likewise, research about family mealtime factors that may vary according to time of day and have 
the potential to influence the overall experience (e.g. perceived importance of eating together, interpersonal interactions at the meal, structure of the meal) or more directly the types and amounts of food consumed (e.g. where food is purchased, how it is served, adolescent involvement in meal preparation) at family breakfast meals is lacking in the peer-reviewed literature ${ }^{(10,11)}$. A search of the literature identified only three previous studies that have examined how eating breakfast together with one's family may be related to nutrition outcomes ${ }^{(10,12,13)}$; just one of these three studies reported on the eating habits of US adolescents ${ }^{(10)}$ and no studies reported on youth residing in rural areas. There is a particular need to better understand the experience of eating together at breakfast among rural US families as school breakfast participation is lower in rural compared with urban areas ${ }^{(14)}$ and because of the potential for informing interventions addressing dietary patterns and the high prevalence of weight-related problems and food insecurity among rural youth ${ }^{(15-19)}$.

In summary, despite growing awareness of the benefits associated with having family meals, little research to date has focused on the breakfast meal or families residing in rural areas. Additional research is needed to better inform the design and targeting of health messages and interventions for rural families and, in particular, for adolescent children who frequently skip the breakfast meal. The current study was conducted to address identified gaps in the literature by providing more information on the prevalence and experience of eating breakfast together as a family among a sample of adolescents enrolled at rural schools in Minnesota, USA. In describing aspects of the family breakfast meal experience, the study may also have important implications for future research designed to investigate mechanisms that link family breakfast meal frequency to adolescent outcomes. The first study aim was to describe the frequency of having family meals at breakfast in relation to the frequency of having family meals at dinner, along with patterns of purchasing family breakfast meals at fast-food restaurants and how family breakfast meals are served. The second aim was to examine associations of the frequency of having family meals at breakfast with demographic characteristics, household food security, adolescent involvement in meal preparation, perceptions of the mealtime experience, and diet quality. Based on the existing literature, it was hypothesized that family meals at breakfast would occur less frequently than family meals at dinner but more frequent family breakfast meals would be similarly related to markers of higher diet quality ${ }^{(10,12,13)}$.

\section{Methods}

\section{Study design and population}

The current study used baseline data from Project BreakFAST (Fueling Academics and Strengthening Teens), a group-randomized trial aimed at increasing school breakfast participation through the implementation of policy and environmental supports in sixteen rural Minnesota high schools ${ }^{(20)}$. All students enrolled in grades 9-10 at the eight intervention and eight control schools were asked to complete a brief screening survey to determine eligibility unless they were absent on the day when data collection took place. Of the 5767 students who completed the screening survey, a total of 2512 students were determined to be eligible based on proficiency in English, having access to a telephone, typically being present at the beginning of the school day, and eating breakfast on no more than three days per school week. Parents of eligible students were notified and asked to contact the study team within $10 \mathrm{~d}$ if they did not want their child to participate. Project BreakFAST invited fifty to seventy-five randomly selected students to participate at each school from the eligible sample with parental consent; ethnic/racial minority students were oversampled to meet a minority enrolment goal of $30 \%$. A total of 904 students provided informed assent and were enrolled in two waves from eight schools in 2012-2013 and from the remaining eight schools in 2013-2014.

Enrolled students were asked to complete height and weight measurements, the baseline survey and $24 \mathrm{~h}$ dietary recalls. Trained research staff measured students' height and weight in a private area at each school and online surveys were independently completed by students in the school computer lab or at home. Three dietary recalls (two weekdays, one weekend day) were administered by research staff over the telephone using the multiple-pass interview technique, a food amount booklet to aid in estimating portion sizes and the Nutrition Data Systems for Research nutrient calculation software ${ }^{(20,21)}$. The analytic sample for the current study includes the 827 students who completed the baseline survey and indicated how often all or most people living in their home had eaten breakfast together over the past week. All study procedures were approved by the University of Minnesota Institutional Review Board Human Subjects Committee and by the principal/superintendent and food-service director at each participating school. Schools also provided administrative data on school breakfast participation and data allowing for identification of enrolled students who received free or reduced-price school meals. The mean proportion of students participating in school breakfast across schools in this sample was just $11 \%$, which translates to the average student eating one school breakfast meal every two weeks. Of possible relevance, the majority of students (60\%) travelled no more than 5 miles to get to school, but $14 \%$ reported travelling more than 10 miles.

\section{Survey development and measures}

The Project BreakFAST survey is a 116-item, self-report instrument that was designed to assess a range of factors of potential relevance to breakfast consumption among 
adolescents. The current study made use of measures that were based on previously established tools and included on the survey to assess: how often adolescents ate breakfast and dinner with other household members ${ }^{(10)}$; how often families of adolescents purchased food from a fast-food restaurant for breakfast ${ }^{(22)}$; how food was served at a typical breakfast meal ${ }^{(23)}$; how often adolescents were involved in preparing breakfast meals ${ }^{(24)}$; attitudes about mealtime importance, interpersonal interactions and structure $^{(25,26)}$; adolescent demographic characteristics ${ }^{(10)}$; and household food security ${ }^{(27)}$.

\section{Family meals}

Frequency of having a family meal at breakfast was assessed with the question: 'During the past 7 days, how many times did all, or most, of the people living in your home eat breakfast together?' A similar question was used to assess how often adolescents had a family meal at dinner. Response categories for each question allowed adolescents to indicate zero to seven times; however, responses were collapsed to never, one to two times and three to seven times for analysis based on the distribution. The questions did not provide detailed definitions for breakfast or dinner in regard to the timing of meals, food or beverage items consumed, or location of consumption.

\section{Purchasing and service of breakfast meals}

As a pilot assessment of food access in the rural region of the Project BreakFAST study found that at least one fast-food restaurant was located within 5 miles of each of three participating schools, consideration was given to the practice of purchasing family meals from a restaurant. Adolescents were asked to report how often their family purchased food from a fast-food restaurant for breakfast in response to the question: 'During the past 7 days, how many times was a family breakfast meal purchased from a fast-food restaurant and eaten together either at the restaurant, in the car or at home?' Response categories allowed adolescents to indicate zero to three or more times. To assess style of meal service, adolescents were asked: 'How is food served at a normal family breakfast?' Response categories were 'we don't eat breakfast as a family', 'food is served family style where everyone can help themselves from food on the table', 'family members serve themselves from the counter or stove top', 'food is put on family members' plates/bowls by whoever cooked it and then served', 'some combination of all these ways' and 'other serving style'.

\section{Preparation of breakfast meals}

Past week frequency of involvement in preparing food for breakfast was assessed using two questions, which separately asked about making breakfast for yourself and helping to make breakfast for your family. Response categories for each question allowed adolescents to indicate zero to seven times.
Mealtime importance, positive interactions and structure The perceived importance of eating breakfast together as a family was assessed by asking adolescents to indicate how strongly they disagreed or agreed with three items: 'In my family, it is important we eat breakfast together'; 'In my family, it is often difficult to find a time when family members can sit down to breakfast together'; and 'I am often too busy to eat breakfast with my family'. Similarly, positive interactions at breakfast meals eaten together as a family was assessed with three items: 'In my family, breakfast time is about more than just getting food; we all talk with each other'; 'In my family, breakfast is a time for talking with other family members'; and 'I enjoy eating breakfast with my family'. The structure at breakfast meals eaten together as a family was assessed with two additional items: 'In my family, manners are important during breakfast' and 'In my family, there are rules at breakfast we are expected to follow'. Responses were dichotomized for analysis ('strongly disagree'/'disagree' $v$. 'strongly agree'/ 'agree') of individual items. Additionally, responses were summed in a manner similar to prior research ${ }^{(25)}$, to form scores with higher values indicating greater agreement in regard to the importance of eating breakfast together with one's family (Cronbach's $\alpha=0.54$ ), experiencing positive interactions at family breakfast meals (Cronbach's $\alpha=0.79$ ) and expectations for structure at family breakfast meals (Cronbach's $\alpha=0.54$ ).

\section{Sociodemographic characteristics}

Adolescent gender, grade level, race, ethnicity and household structure were assessed by self-report. Household structure was assessed with the question: 'Which adults do you live with?' Participants were instructed to select all applicable categories from the following response options: 'my mother', 'my father', 'sometimes with my mother, sometimes with my father (they have separate homes)', 'stepmother', 'stepfather', 'other adult relatives (like grandparents)' and 'other, not related'. Administrative data on receipt of free/reducedprice school meals were linked to the survey data using student identification numbers and contributed a marker of socio-economic status.

\section{Household food security}

Food security was assessed using nine questions adapted from the US Food Security Survey Module. The questions asked adolescents about the availability of food at home in the last $30 \mathrm{~d}$ and how often it had been necessary to cut back on the amount they ate due to a lack of money for food (e.g. 'Has the size of your meals been cut because your family didn't have enough money for food?'). Response categories were 'a lot', 'sometimes' and 'never'. The questions were previously validated and determined to be a reliable measure of food security status in a sample of 345 adolescents ${ }^{(27)}$. In the Project BreakFAST sample, 
the Cronbach's $\alpha$ for the nine questions indicated high internal consistency $(r=0 \cdot 91)$.

\section{Dietary recalls}

Most adolescent participants ( $n$ 739) additionally completed at least one $24 \mathrm{~h}$ dietary recall and the majority of participants completed multiple recalls ( $n 618$ completed three recalls, $n 58$ completed two recalls, $n 63$ completed one recall). Average intake values were generated when multiple recalls were completed and the Healthy Eating Index 2010 (HEI-2010) was used to assess diet quality. The HEI-2010 is a measure of diet quality in terms of conformance to the Dietary Guidelines for Americans and US Department of Agriculture Food Patterns ${ }^{(28)}$. For the current study, analyses focused on overall diet quality scores (range: 0-100) and selected component scores reflecting intakes of vegetables (range: 0-5), whole fruit (range: 0-5), whole grains (range: 0-10), refined grains (range: 0-10), dairy (range: 0-10), total protein (range: 0-5), fatty acids (range: 0-10), sodium (range: 0-10) and empty calories (range: 0-20). For all HEI-2010 components, higher scores indicate closer conformance with dietary guidance. A recent evaluation of the HEI-2010 supported its validity and reliability for assessing diet quality ${ }^{(29)}$.

\section{Statistical analysis}

All analyses were conducted using the statistical software package SAS version 9.3 (2011). Descriptive statistics were first calculated to examine patterns of eating breakfast together, meal purchasing and meal service. Two-sample $t$ tests were used to identify differences in mean frequency of eating together according to demographic characteristics, food security status and meal preparation behaviours. Perceptions of mealtime importance, positive interactions and structure were summarized using percentage agreement with each of the statements and the $\chi^{2}$ test statistic was used to evaluate overall differences in perceptions across breakfast meal frequency categories (never, 1-2 times, 3-7 times). Additionally, linear mixed models were used to examine associations between frequency of eating breakfast together and scores representing importance, positive interactions and structure. Models included a random effect of school to account for clustering within schools and fixed effects of gender, grade level, race, ethnicity, household structure, free/reducedprice school meal status and household food security status. Similar linear mixed models were used to examine the associations between frequency of eating breakfast together and the HEI-2010 scores for boys and girls separately; models were stratified by gender based on prior family meals research ${ }^{(6)}$. Least-square means and their standard errors with type 3 tests were used to interpret practical and statistical significance. Two-sided tests were used to evaluate statistical significance based on a $95 \%$ confidence level.

\section{Results}

\section{Frequency of eating breakfast together, meal purchasing and meal service}

On average, this sample of adolescent breakfast skippers reported eating together with 'all or most' of their family 1.3 (SD 1.9) times at breakfast and 4.5 (SD 2.2) times at dinner in the past week. Family dinner frequency was directly associated with family breakfast frequency $(P<0.001)$; adolescents who reported never having a family breakfast in the past week had an average family dinner frequency of 3.9 times as compared with an average family dinner frequency of 5.4 times among adolescents who reported three to seven family breakfast meals.

The average frequency of eating breakfast together was similar across most demographic subgroups and food security status; however, differences were found by race and ethnicity (Table 1). Adolescents who reported a race other than white and their ethnicity as Hispanic had higher frequencies of eating breakfast together than adolescents of white race and non-Hispanic ethnic backgrounds, respectively.

Among adolescents who had at least one family breakfast meal in the past week, the distribution for reported frequency of purchasing the meal from a fast-food restaurant was as follows: $78 \%$ zero times ( $n$ 303), $14 \%$ one time ( $n$ 54), $7 \%$ two times $(n$ 26) and $1 \%$ three or more times $(n$ 5). In reference to a normal family breakfast, the distribution of breakfast meal service styles among adolescents who reported ever eating breakfast as a family was as follows: $27 \%$ family style where everyone can help themselves ( $n$ 94), $25 \%$ family members serve themselves from the counter or stove ( $n$ 89), $13 \%$ food is put on family members' plates or bowls by whoever cooked ( $n$ 45), $22 \%$ some combination of all these ways ( $n$ 78) and $3 \%$ other serving style $(n 9)$.

\section{Preparation of breakfast meals by frequency of eating breakfast together}

On average, adolescents reported making their own breakfast $2 \cdot 2$ (SD 2.1) times and helping to make breakfast for their family 0.6 (SD 1.3) times in the past week. The average frequency of eating breakfast together with family members was positively associated with adolescent preparation of breakfast meals for their own consumption $(P<0 \cdot 001)$ and for their family $(P<0 \cdot 001)$. For example, the average past week frequency of making your own breakfast was 1.9 ( $\mathrm{SD} 2 \cdot 1$ ) times among adolescents who never ate breakfast together with their family compared with $2 \cdot 8$ (SD 2.1) times among those who ate breakfast together with their family three to seven times during the week.

\section{Adolescents' attitudes about mealtime importance, positive interactions and structure by frequency of eating breakfast together}

The majority of adolescents agreed or strongly agreed that it is often difficult for family members to find a time when 
Table 1 Frequency of eating breakfast together as a family in the past week according to sociodemographic characteristics of adolescents in rural Minnesota, USA, 2012-2014

\begin{tabular}{|c|c|c|c|c|c|c|c|}
\hline & \multirow[b]{2}{*}{$n$} & \multicolumn{3}{|c|}{$\begin{array}{l}\text { Frequency of family breakfast meals in the } \\
\text { past week }\end{array}$} & \multirow[b]{2}{*}{$\begin{array}{l}\text { Mean } \\
\text { frequency }\end{array}$} & \multirow[b]{2}{*}{ SD } & \multirow[b]{2}{*}{$P$ value* } \\
\hline & & $\begin{array}{c}\text { Never } \\
(\%)\end{array}$ & $\begin{array}{l}1-2 \text { times } \\
(\%)\end{array}$ & $\begin{array}{l}3-7 \text { times } \\
(\%)\end{array}$ & & & \\
\hline Overall & 827 & 53 & 26 & 21 & $1 \cdot 3$ & 1.9 & \\
\hline Gender & & & & & & & 0.05 \\
\hline Boys & 371 & 51 & 24 & 25 & 1.5 & $2 \cdot 0$ & \\
\hline Girls & 456 & 54 & 28 & 18 & $1 \cdot 2$ & 1.8 & \\
\hline School grade level & & & & & & & 0.08 \\
\hline Grade 9 & 406 & 52 & 24 & 24 & 1.5 & $2 \cdot 0$ & \\
\hline Grade 10 & 421 & 54 & 29 & 18 & $1 \cdot 2$ & $1 \cdot 8$ & \\
\hline Race & & & & & & & 0.002 \\
\hline Non-white & 234 & 46 & 25 & 29 & $1 \cdot 7$ & $2 \cdot 1$ & \\
\hline White & 555 & 56 & 26 & 17 & $1 \cdot 2$ & $1 \cdot 8$ & \\
\hline Ethnicity & & & & & & & 0.02 \\
\hline Hispanic & 107 & 37 & 35 & 28 & $1 \cdot 7$ & 1.9 & \\
\hline Non-Hispanic & 672 & 55 & 26 & 20 & $1 \cdot 3$ & 1.9 & \\
\hline Household structure & & & & & & & 0.94 \\
\hline Live with two parents & 593 & 52 & 27 & 21 & $1 \cdot 3$ & 1.9 & \\
\hline Other household structure & 233 & 55 & 24 & 21 & 1.4 & $2 \cdot 0$ & \\
\hline Free/reduced-price school meals & & & & & & & 0.30 \\
\hline No & 527 & 54 & 26 & 19 & $1 \cdot 3$ & 1.9 & \\
\hline Yes & 299 & 50 & 26 & 24 & 1.4 & 1.9 & \\
\hline Household food security & & & & & & & 0.82 \\
\hline Food secure & 677 & 53 & 27 & 20 & 1.4 & $2 \cdot 0$ & \\
\hline Food insecure & 112 & 51 & 24 & 25 & $1 \cdot 4$ & $1 \cdot 8$ & \\
\hline
\end{tabular}

*Estimates are unadjusted percentages and mean frequencies. $P$ values are based on two-sample $t$ tests.

Table 2 Perceptions of family breakfast importance, positive interactions and structure among adolescents in rural Minnesota, USA, 2012-2014

\begin{tabular}{|c|c|c|c|c|}
\hline & \multicolumn{3}{|c|}{$\begin{array}{l}\text { Agreement }(\%) \text { by family breakfast } \\
\text { frequency in the past week }\end{array}$} & \multirow[b]{2}{*}{$P$ value } \\
\hline & $\begin{array}{l}\text { Never } \\
(n \text { 437) }\end{array}$ & $\begin{array}{l}1-2 \text { times } \\
(n 217)\end{array}$ & $\begin{array}{l}3-7 \text { times } \\
(n \text { 173) }\end{array}$ & \\
\hline It is important we eat breakfast together & 11 & 28 & 43 & $<0.001$ \\
\hline It is often difficult to find a time when family members can sit down to breakfast together & 77 & 65 & 45 & $<0.001$ \\
\hline I am often too busy to eat breakfast with my family & 70 & 53 & 38 & $<0.001$ \\
\hline Breakfast is a time for talking with other family members & 17 & 39 & 44 & $<0.001$ \\
\hline I enjoy eating breakfast with my family & 56 & 80 & 81 & $<0.001$ \\
\hline Manners are important during breakfast & 59 & 69 & 69 & 0.01 \\
\hline There are rules at breakfast we are expected to follow & 12 & 25 & 31 & $<0.001$ \\
\hline
\end{tabular}

they can sit down to breakfast together (67\%), they are often too busy to eat breakfast with their family members (59\%), they enjoy eating breakfast with their family (67\%) and manners are important during breakfast (63\%). Agreement was less common for statements regarding the importance of eating breakfast together (22\%), breakfast being a time to talk with other family members (29\%) and having rules they are expected to follow at breakfast (19\%).

Agreement with each of the individual statements relating to mealtime importance, positive interactions and structure was related to frequency of eating breakfast together with family members (Table $2 ; P \leq 0 \cdot 01$ for each test of overall differences). Models accounting for sociodemographic characteristics, household food security status and school as a random effect further showed that frequency of eating breakfast together was related to attitude scores indicating higher perceived importance for time, more positive interactions and greater structure at family breakfast meals (Table $3 ; P \leq 0.01$ for each test of overall differences). 
Table 3 Perceptions of family breakfast importance, positive interactions and structure among adolescents in rural Minnesota, USA, 2012-2014

\begin{tabular}{|c|c|c|c|c|c|c|c|}
\hline & \multicolumn{6}{|c|}{ Family breakfast frequency in the past week ${ }^{*}$} & \multirow[b]{3}{*}{$P$ value } \\
\hline & \multicolumn{2}{|c|}{ Never ( $n$ 437) } & \multicolumn{2}{|c|}{$1-2$ times ( $n$ 217) } & \multicolumn{2}{|c|}{ 3-7 times $(n 173)$} & \\
\hline & Mean & SE & Mean & SE & Mean & SE & \\
\hline Importance (range: $3-12$ ) & $6 \cdot 1^{\mathrm{a}, \mathrm{c}}$ & 0.2 & $7 \cdot 0^{\mathrm{b}, \mathrm{c}}$ & 0.2 & $7 \cdot 8^{\mathrm{a}, \mathrm{b}}$ & 0.2 & $<0.001$ \\
\hline Positive interactions (range: $3-12$ ) & $6 \cdot 3^{\mathrm{a}, \mathrm{b}}$ & 0.2 & $7.5^{\mathrm{b}}$ & 0.2 & $7 \cdot 8^{\mathrm{a}}$ & 0.2 & $<0.001$ \\
\hline Structure (range: $2-8$ ) & $4 \cdot 2^{a, b}$ & 0.1 & $4 \cdot 8^{\mathrm{b}}$ & 0.1 & $4.9^{\mathrm{a}}$ & 0.1 & $<0.001$ \\
\hline
\end{tabular}

${ }^{a, b, c}$ Mean values within a row with unlike superscript letters were significantly different $(P<0.05)$.

${ }^{\star}$ The model includes fixed effects for gender, school grade level, race, ethnicity, household structure, free/reduced-price school meal eligibility and household food security status, along with a random effect representing school.

Table 4 Adolescent boys' adjusted* Healthy Eating Index 2010 (HEl-2010) scores by past week frequency of eating breakfast together as a family in rural Minnesota, USA, 2012-2014

\begin{tabular}{|c|c|c|c|c|c|c|c|}
\hline & \multicolumn{6}{|c|}{ Family breakfast frequency in the past week } & \multirow[b]{3}{*}{$P$ value } \\
\hline & \multicolumn{2}{|c|}{ Never ( $n$ 149) } & \multicolumn{2}{|c|}{$1-2$ times $(n 72)$} & \multicolumn{2}{|c|}{ 3-7 times $(n 78)$} & \\
\hline & Mean & SE & Mean & SE & Mean & SE & \\
\hline Total HEI-2010 score (range: 0-100) & $52 \cdot 3$ & 1.6 & $50 \cdot 5$ & 1.7 & $52 \cdot 0$ & 1.7 & 0.44 \\
\hline Vegetable score (range: $0-5$ ) & $2 \cdot 0$ & 0.2 & $2 \cdot 3$ & 0.2 & $2 \cdot 2$ & 0.2 & 0.72 \\
\hline Whole fruit score (range: $0-5$ ) & $1.9^{\mathrm{a}}$ & 0.3 & $1 \cdot 3^{\mathrm{b}}$ & 0.3 & $1.7^{\mathrm{a}, \mathrm{c}}$ & 0.3 & 0.02 \\
\hline Whole grains score (range: $0-5$ ) & 3.4 & 0.5 & $3 \cdot 1$ & 0.6 & 4.0 & 0.6 & 0.25 \\
\hline Refined grains score (range: $0-10$ ) & $5 \cdot 0$ & 0.6 & 4.7 & 0.6 & 4.2 & 0.6 & 0.32 \\
\hline Dairy score (range: $0-10$ ) & 7.9 & 0.4 & 7.4 & 0.4 & $8 \cdot 1$ & 0.4 & 0.20 \\
\hline Protein foods score (range: $0-5$ ) & 4.2 & 0.2 & 4.3 & 0.2 & $4 \cdot 1$ & 0.2 & 0.69 \\
\hline Fatty acid ratio score (range: $0-10$ ) & $3 \cdot 8$ & 0.5 & 3.4 & 0.5 & 3.5 & 0.5 & 0.66 \\
\hline Sodium score (range: $0-10$ ) & $3 \cdot 6$ & 0.5 & 4.0 & 0.5 & 3.4 & 0.5 & 0.48 \\
\hline Empty calories score† (range: 0-20) & $16 \cdot 0$ & 0.6 & $15 \cdot 7$ & 0.6 & $16 \cdot 8$ & 0.6 & 0.17 \\
\hline
\end{tabular}

${ }^{a, b, c}$ Mean values within a row with unlike superscript letters were significantly different $(P<0.05)$.

*The model includes fixed effects for school grade level, race, ethnicity, household structure, free/reduced-price school meal eligibility and household food security status, along with a random effect representing school.

†Solid fats, alcohol and added sugars.

\section{Adolescents' diet quality by frequency of eating breakfast together}

Models accounting for sociodemographic characteristics, household food security status and school as a random effect showed the frequency of eating breakfast together was unrelated to most markers of diet quality among adolescent boys (Table 4) and girls (Table 5) who reported skipping breakfast on two or more days per week. Differences in component HEI-2010 scores by frequency of eating breakfast together were identified only for whole fruit $(P=0.02)$ among boys and refined grains $(P=0.001)$ and empty calories $(P=0.008)$ among girls. Adolescent boys who ate breakfast together with their family one to two times in the past week had poorer scores for whole fruit than their peers who never ate breakfast with their family. For adolescent girls, frequency of eating breakfast together was associated with poorer scores for refined grains but with better scores for empty calories (i.e. consumed less energy from solid fats, alcohol and added sugars).

\section{Discussion}

The present study described patterns and experiences of eating breakfast together among rural families along with associations between family breakfast frequency and markers of adolescent dietary quality. The results show that family breakfast meals contribute to the shared mealtime experiences of adolescent breakfast skippers and, in line with some previous research, occur most frequently in the homes of adolescents from ethnic/racial minority backgrounds ${ }^{(10)}$. Although the majority of adolescents reported they enjoy eating breakfast together with their family, scheduling difficulties were common and only $22 \%$ of adolescents agreed it was important to eat breakfast together. The purchasing of a family breakfast meal from a fast-food restaurant was reported by nearly a quarter of adolescents who had a family breakfast meal in the past week while the average frequency of helping to prepare food for the breakfast meal was fewer than once per week. Participation in family breakfast meals was unrelated to most markers of dietary quality, suggesting the need for additional research to build a greater understanding of the practice among rural families and behavioural modifications that could be implemented to better support healthy food choices for adolescents who frequently skip eating breakfast.

While only two previous studies in adolescents and one study in younger children have examined associations between family breakfast frequency and markers of 
Table 5 Adolescent girls' adjusted* Healthy Eating Index 2010 (HEl-2010) scores by past week frequency of eating breakfast together as a family in rural Minnesota, USA, 2012-2014

\begin{tabular}{|c|c|c|c|c|c|c|c|}
\hline & \multicolumn{6}{|c|}{ Family breakfast frequency in the past week } & \multirow[b]{3}{*}{$P$ value } \\
\hline & \multicolumn{2}{|c|}{ Never (n 226) } & \multicolumn{2}{|c|}{$1-2$ times $(n 116)$} & \multicolumn{2}{|c|}{ 3-7 times $(n 71)$} & \\
\hline & Mean & SE & Mean & SE & Mean & $\mathrm{SE}$ & \\
\hline Total HEI-2010 score (range: 0-100) & 53.8 & 1.4 & $54 \cdot 0$ & 1.6 & $54 \cdot 0$ & 1.8 & 0.99 \\
\hline Vegetable score (range: 0-5) & $2 \cdot 1$ & 0.1 & $2 \cdot 1$ & 0.2 & $2 \cdot 0$ & 0.2 & 0.77 \\
\hline Whole fruit score (range: $0-5$ ) & $2 \cdot 4$ & 0.2 & $2 \cdot 1$ & 0.3 & $2 \cdot 2$ & 0.3 & 0.37 \\
\hline Whole grains score (range: $0-5$ ) & $3 \cdot 6$ & 0.4 & $3 \cdot 4$ & 0.4 & $4 \cdot 0$ & 0.5 & 0.41 \\
\hline Refined grains score (range: $0-10$ ) & $5 \cdot 7^{\mathrm{a}}$ & 0.4 & $5 \cdot 2^{\mathrm{a}, \mathrm{b}}$ & 0.4 & $4 \cdot 0^{\mathrm{C}}$ & 0.5 & 0.001 \\
\hline Dairy score (range: $0-10$ ) & $7 \cdot 8$ & 0.3 & 7.9 & 0.3 & $8 \cdot 6$ & 0.4 & 0.06 \\
\hline Protein foods score (range: $0-5$ ) & 3.9 & 0.2 & $4 \cdot 2$ & 0.2 & 3.7 & 0.2 & 0.08 \\
\hline Fatty acid ratio score (range: $0-10$ ) & $3 \cdot 4$ & 0.3 & 3.7 & 0.4 & 3.4 & 0.4 & 0.82 \\
\hline Sodium score (range: $0-10$ ) & $5 \cdot 1$ & 0.4 & $4 \cdot 8$ & 0.4 & 4.5 & 0.5 & 0.35 \\
\hline Empty calories score† (range: 0-20) & $14 \cdot 5^{\mathrm{a}}$ & 0.5 & $15 \cdot 4^{\mathrm{a}, \mathrm{b}}$ & 0.6 & $16 \cdot 2^{\mathrm{b}}$ & 0.6 & 0.008 \\
\hline
\end{tabular}

${ }^{a, b, c}$ Mean values within a row with unlike superscript letters were significantly different $(P<0 \cdot 05)$.

*The model includes fixed effects for school grade level, race, ethnicity, household structure, free/reduced-price school meal eligibility and household food security status, along with a random effect representing school.

†Solid fats, alcohol and added sugars.

dietary quality, all three studies found some evidence that eating breakfast together was related to better nutritional outcomes $^{(10,12,13)}$. For example, a study among 2793 students in grades 6 to 12 in the Minneapolis-St. Paul metropolitan area of Minnesota showed that family breakfast frequency was associated with higher usual intakes of fruit, whole grains and fibre ${ }^{(10)}$. The absence of a relationship between eating breakfast together as a family and most measures of adolescent dietary intake in the sample for the current study might be explained by methodological differences and, in part, by the unique nature of the sample. Eating breakfast on no more than three days in a school week was an eligibility requirement for participation in Project BreakFAST and not being hungry in the morning was reported as a common barrier $^{(30)}$. Most adolescents who participated in family breakfast meals (73\%) therefore reported a frequency of three or fewer times in the past week, and it is possible that adolescents who participated in family breakfast meals consumed little food at the meals.

The findings in regard to meal purchasing, preparation and service are also important to consider within the context of prior research. Frequent purchasing of family meals from a fast-food restaurant is a practice associated with poor diet quality among youth and parents ${ }^{(31,32)}$. While secular decreases in the frequency of eating at fast-food restaurants have been observed over the past decade, similar decreases in the overall frequency of purchasing fast food for family meals have not been observed $^{(22)}$. The current study adds to this literature by more specifically describing the practice at breakfast among families residing in rural areas and demonstrating it is not uncommon in a given week for families to purchase at least one breakfast meal at a fast-food restaurant. In contrast, there is growing evidence that adolescent involvement in meal preparation is associated with markers of better diet quality ${ }^{(24,33)}$. The frequency of adolescent involvement in food preparation was positively associated with family breakfast frequency but, even among those who had three or more family breakfast meals in a given week, the average frequency of involvement in food preparation was just 1.3 times. Together these findings regarding meal purchasing and preparation habits could help to further explain the lack of an association between family breakfast frequency and adolescent dietary quality in the study sample and suggest behavioural modifications should be evaluated as part of interventions. Less is known about the potential influence of meal service style on dietary quality but the finding that a self-service style (i.e. everyone helps themselves from food on the table, counter or stove top) is utilized by more than half of families that eat together also has implications for the design of interventions and messaging to parents. Related research regarding the influence of home food availability and accessibility suggests that when young people are provided the opportunity to serve themselves it is important to make healthy options the easiest options and provide tableware that does not promote excessive portions (e.g. 4 oz juice glass, $8 \mathrm{oz}$ bowl) ${ }^{(34)}$. Therefore, the results suggest it will be important as part of interventions promoting family breakfast meals to encourage and provide specific suggestions for parents to help them in making healthy breakfast food options readily accessible in their home; limit the accessibility of energy-dense, nutrient-poor alternatives; and provide breakfast tableware of a reasonable size.

Strengths and limitations of the current study should be considered in interpreting the findings. Strengths included the breadth of reliable measures used to assess mealtime experiences, the focus on adolescents enrolled at rural schools and the comprehensive examination of overall diet quality using the HEI-2010. The present study was 
among the first to describe adolescents' perceptions regarding the importance of eating breakfast together with their family, interpersonal interactions at family breakfast meals and structure of family breakfast meals. Additionally, the study uniquely provided information about adolescents' involvement in preparing food for breakfast and how families that eat breakfast together manage the service of meals. The focus on adolescents enrolled at rural schools is noteworthy as most other research on family meals has been carried out in urban populations $^{(2,4,10,35)}$. Nutrition and weight are priority areas for improving the health of rural youth and thus their experiences are particularly important to understand in developing interventions ${ }^{(36)}$. Diet quality was assessed using $24 \mathrm{~h}$ dietary recalls and the established HEI-2010 scoring metric ${ }^{(29)}$.

Despite the rigour of the dietary assessment based on the HEI-2010, the study did not collect sufficient data to allow for description of the foods and beverages consumed at family breakfast meals. Further, the term 'breakfast' was not defined for participants as has been proposed by experts ${ }^{(37)}$ and it was not possible to compare family breakfast meals with breakfast meals consumed in other contexts in regard to nutrient intake or the types of foods and beverages consumed. The breadth of information collected as part of the Project BreakFAST survey precluded asking about the days of the week when family breakfast meals or adolescent involvement in preparing food for breakfast occurred, other aspects of adolescent involvement in food preparation, details regarding the purchasing of family breakfast meals at fastfood restaurants, or the contextual factors that may be important to address in developing interventions that target these behaviours. It is also possible that social desirability influenced the responses of adolescent participants to measures of family breakfast meals included on the survey and their report of dietary intake. Caution should be used in making generalizations to youth from other areas as the data were collected in one Midwest state and there may be regional differences in family breakfast patterns. Additionally, it is possible the exclusion criteria for Project BreakFAST produced a sample with family breakfast patterns that are not representative of those among adolescents residing in rural areas.

\section{Conclusion}

The results of the present study indicate family meals may represent one important context of opportunity to address in designing messages and interventions to promote healthy breakfast eating patterns among rural youth and particularly for those targeted to ethnic/racial minority families. Although the current study did not find a relationship between family breakfast frequency and dietary quality, the results showed that nearly half of rural families have at least one family breakfast meal in a given week and the majority of adolescents enjoy eating breakfast with their family. Additional research should be carried out to confirm the observed relationships in samples that include and can compare breakfast skippers, breakfast eaters who do not eat with their family and breakfast eaters who eat with their family. Further research will also be important to better inform and evaluate strategies for promoting healthy food patterns as part of family breakfast meals. For example, it may be beneficial for health professionals to provide families with ideas for quick, healthy meal options that could replace the purchase of food at fast-food restaurants and that adolescents could bring to school for eating at a later time if they are not hungry at the family mealtime. Future research should explore whether being at the table while other family members consume breakfast could provide an important opportunity for communication and learning about healthy food choices even if an adolescent is not hungry and chooses, for example, to only drink a glass of milk or $100 \%$ juice during the family meal. It is further likely, based on the results reported here, that participating in family breakfast meals may provide an opportunity for adolescents to build their skills and interest in preparing food. Interventions for families that incorporate messages around eating together at breakfast should thus consider building on related research $^{(24,38,39)}$ by further evaluating the practice of providing guidance for adolescents and their parents to promote the practice of preparing healthy foods at home.

As previous research has linked overall family meal frequency to outcomes other than nutritional health, future studies should also consider whether family breakfast frequency is associated with outcomes such as fewer disordered eating behaviours, better psychosocial health and higher school performance ${ }^{(40)}$. If family breakfast frequency is found to promote multiple aspects of adolescent health, it may be particularly important for school and health professionals to use the results of the current study in combination with other research to inform practices that support families in eating breakfast together. The finding, for example, that $59 \%$ of adolescents were often too busy to eat breakfast with their family members emphasizes the potential benefits of advocating for delayed school start times for high-school students so that young people have adequate time for sleep and sharing time with their family in the morning. Prior populationbased research has similarly reported the perception of being too busy in the morning to eat a healthy breakfast is common among adolescents ${ }^{(41,42)}$. Although the American Academy of Pediatrics now recommends that schools aim to start no earlier than 08.30 hours in the morning, a 2011-2012 national survey found this was the case in only $14.4 \%$ of US high schools ${ }^{(43,44)}$. Family breakfast frequency was not related to the measure of household food security included in the current study but insecure access to affordable, healthy food may be yet another 
barrier for health professionals to address in promoting shared meals ${ }^{(45,46)}$. Future studies should consider using qualitative assessments in an effort to fully assess the potential impact of food security on sharing mealtimes. Finally, there is also a need for qualitative research to explore in greater depth the attitudes and preferences of adolescents in regard to how their families can best support them in fuelling their bodies with healthy food at breakfast and possible cultural differences among young people representing various ethnic/racial backgrounds.

\section{Acknowledgements}

Financial support: This work was supported by the National Heart, Lung, and Blood Institute (Principal Investigator: M.S.N., grant number R01HL113235). The content is solely the responsibility of the authors and does not necessarily represent the official views of the National Heart, Lung, and Blood Institute or the National Institutes of Health. Conflict of interest: None. Authorship: N.L. conceptualized the analysis and drafted the manuscript. Q.W. conducted the statistical analysis. J.M.B. contributed to the development of survey measures and helped to conceptualize the analysis. A.S. was involved in data collection and organization. M.S.N. conceptualized the larger Project BreakFAST study design and oversaw data collection. All authors contributed to the interpretation of results and manuscript revisions. All authors have reviewed and approved the content of the submission. Ethics of buman subject participation: All study procedures were approved by the University of Minnesota Institutional Review Board Human Subjects Committee and by the principal/superintendent and food-service director at each participating school.

\section{References}

1. Woodruff S \& Hanning R (2009) Associations between family dinner frequency and specific food behaviors among grade six, seven, and eight students from Ontario and Nova Scotia. J Adolesc Health 44, 431-436.

2. Fulkerson J, Kubik M, Story M et al. (2009) Are there nutritional and other benefits associated with family meals among at-risk youth? J Adolesc Health 45, 389-395.

3. Gillman M, Rifas-Shiman S, Frazier A et al. (2000) Family dinner and diet quality among older children and adolescents. Arch Fam Med 9, 235-240.

4. Neumark-Sztainer D, Hannan P, Story M et al. (2003) Family meal patterns: associations with sociodemographic characteristics and improved dietary intake among adolescents. J Am Diet Assoc 103, 317-322.

5. Videon $\mathrm{T} \&$ Manning C (2003) Influences on adolescent eating patterns: the importance of family meals. J Adolesc Health 32, 365-373.

6. Burgess-Champoux T, Larson N, Neumark-Sztainer D et al. (2009) Are family meal patterns associated with overall diet quality during the transition from early to middle adolescence? J Nutr Educ Behav 41, 79-86.
7. Boutelle K, Lytle L, Murray D et al. (2001) Perceptions of the family mealtime environment and adolescent mealtime behavior: do adults and adolescents agree? J Nutr Educ Behav 33, 128-133.

8. Fulkerson JA, Neumark-Sztainer D \& Story M (2006) Adolescent and parent views of family meals. J Am Diet Assoc 106, 526-532.

9. Rampersaud G, Pereira M, Girard B et al. (2005) Breakfast habits, nutritional status, body weight, and academic performance in children and adolescents. J Am Diet Assoc 105, $743-760$.

10. Larson N, MacLehose R, Fulkerson J et al. (2013) Eating breakfast and dinner together as a family: associations with sociodemographic characteristics and implications for diet quality and weight status. J Acad Nutr Diet 113, 1601-1609.

11. Fulkerson J, Larson N, Horning $\mathrm{M}$ et al. (2014) A review of associations between family or shared meal frequency and dietary and weight status outcomes across the lifespan. J Nutr Educ Behav 46, 2-19.

12. Woodruff S, Hanning R, McGoldrick K et al. (2010) Healthy Eating Index-C is positively associated with family dinner frequency among students in grades 6-8 from Southern Ontario, Canada. Eur J Clin Nutr 64, 454-460.

13. Andaya A, Arredondo E, Alcaraz J et al. (2011) The association between family meals, TV viewing during meals, and fruit, vegetables, soda, and chips intake among Latino children. J Nutr Educ Behav 43, 308-315.

14. Carson J (2015) Many Eligible Children Don't Participte in School Nutrition Programs: Reauthorization Offers Opportunities to Improve. Durham, NH: Carsey School of Public Policy, University of New Hampshire; available at https:// carsey.unh.edu/publication/child-school-nutrition-programs

15. Johnson J \& Johnson A (2015) Urban-rural differences in childhood and adolescent obesity in the United States: a systematic review and meta-analysis. Child Obes 11, 233-241.

16. Liu J, Bennett K, Harun N et al. (2008) Urban-rural differences in overweight status and physical inactivity among US children aged 10-17 years. J Rural Health 24, 407-415.

17. Liu J, Jones S, Sun H et al. (2012) Diet, physical activity, and sedentary behaviors as risk factors for childhood obesity: an urban and rural comparison. Child Obes 8, 440-448.

18. Goodwin D, Knol L, Eddy J et al. (2006) Sociodemographic correlates of overall quality of dietary intake of US adolescents. Nutr Res 26, 105-110.

19. Coleman-Jensen A, Rabbitt M, Gregory C et al. (2015) Household Food Security in the United States in 2014. Economic Research Report no. ERR-194. Washington, DC: US Department of Agriculture, Econcomic Research Service; available at http://www.ers.usda.gov/publications/ err-economic-research-report/err194.aspx

20. Nanney MS, Shanafelt A, Wang Q et al. (2016) Project BreakFAST: rationale, design, and recruitment and enrollment methods of a randomized controlled trial to evaluate an intervention to improve School Breakfast Program participation in rural high schools. Contemp Clin Trials Commun (In the Press); available at http://www. sciencedirect.com/science/article/pii/S2451865415300399

21. Nutrition Coordinating Center, University of Minnesota (2014) Nutrition Data System for Research (NDSR) Software. http://www.ncc.umn.edu/products/

22. Larson N, Hannan P, Fulkerson J et al. (2014) Secular trends in fast-food restaurant use among adolescents and maternal caregivers from 1999 to 2010. Am J Public Health 104, e62-e69.

23. Neumark-Sztainer D, Maclehose R, Loth K et al. (2014) What's for dinner? Types of food served at family dinner differ across parent and family characteristics. Public Health Nutr 17, 145-155.

24. Larson NI, Story M, Eisenberg ME et al. (2006) Food preparation and purchasing roles among adolescents: 
associations with sociodemographic characteristics and diet quality. J Am Diet Assoc 106, 211-228.

25. Neumark-Sztainer D, Wall M, Story M et al. (2004) Are family meal patterns associated with disordered eating behaviors among adolescents? J Adolesc Health 35, 350-359.

26. Hogen P (1988) The relationship between individual psychological characteristics and factors associated with family use of food as predictors of disturbed eating attitudes and behaviors in adolescents. PhD Thesis, University of Hartford.

27. Connell C, Nord M, Lofton K et al. (2004) Food security of older children can be assessed using a standardized survey instrument. J Nutr 134, 2566-2572.

28. Guenther P, Casavale K, Reedy J et al. (2013) Update of the Healthy Eating Index: HEI-2010. J Acad Nutr Diet 113, 569-580.

29. Guenther P, Kirkpatrick S, Reedy J et al. (2014) The Healthy Eating Index-2010 is a valid and reliable measure of diet quality according to the 2010 Dietary Guidelines for Americans. J Nutr 144, 399-407.

30. Hearst M, Shanafelt A, Wang Q et al. (2016) Barriers, benefits and behaviors related to breakfast consumption among rural adolescents. J Sch Health 86, 187-194.

31. Fulkerson J, Farbakhsh K, Lytle L et al. (2011) Away-fromhome family dinner sources and associations with weight status, body composition, and related biomarkers of chronic disease among adolescents and their parents. J Am Diet Assoc 111, 1892-1897.

32. Boutelle K, Fulkerson J, Neumark-Sztainer D et al. (2007) Fast food for family meals: relationships with parent and adolescent food intake, home food environment and weight status. Public Health Nutr 10, 16-23.

33. Vaitkeviciute R, Ball L \& Harris N (2015) The relationship between food literacy and dietary intake in adolescents: a systematic review. Public Health Nutr 18, 649-658.

34. Larson N \& Story M (2009) A review of environmental influences on food choices. Ann Behav Med 38, Suppl. 1, S56-S73.

35. Berge J, Jin S, Hannan P et al. (2013) Structural and interpersonal characteristics of family meals: associations with adolescent BMI and dietary patterns. J Acad Nutr Diet $\mathbf{1 1 3}$, 816-822.

36. Bolin J \& Bellamy G (2012) Rural Healthy People 2020. https://sph.tamhsc.edu/srhrc/docs/rhp2020.pdf (accessed February 2016).

37. O'Neil C, Byrd-Bredbenner C, Hayes D et al. (2014) The role of breakfast in health: definition and criteria for a quality breakfast. J Acad Nutr Diet 114, 12 Suppl., S8-S26.

38. Chu Y, Farmer A, Fung C et al. (2013) Involvement in home meal preparation is associated with food preference and self-efficacy among Canadian children. Public Health Nutr 16, 108-112.

39. Woodruff S \& Kirby A (2013) The associations among family meal frequency, food preparation frequency, self-efficacy for cooking, and food preparation techniques in children and adolescents. J Nutr Educ Behav 45, 296-303.

40. Neumark-Sztainer D, Larson N, Fulkerson J et al. (2010) Family meals and adolescents: what have we learned from Project EAT (Eating Among Teens)? Public Health Nutr 13, $1113-1121$.

41. Larson N, Story M, Wall M et al. (2006) Calcium and dairy intakes of adolescents are associated with their home environment, taste preferences, personal health beliefs, and meal patterns. J Am Diet Assoc 106, 1816-1824.

42. Mullan B, Wong C, Kothe E et al. (2014) An examination of the demographic predictors of adolescent breakfast consumption, content, and context. BMC Public Health 14, 264.

43. Wheaton A, Ferro G \& Croft J (2015) School start times for middle school and high school students - United States, 2011-12 school year. Morb Mortal Wkly Rep 64, 809-813.

44. Adolescent Sleep Working Group; Committee on Adolescence; Council on School Health (2014) School start times for adolescents. Pediatrics 134, 642-649.

45. Bruening M, MacLehose R, Loth K et al. (2012) Feeding a family in a recession: food insecurity among Minnesota parents. Am J Public Health 102, 520-526.

46. Widome R, Neumark-Sztainer D, Hannan P et al. (2009) Eating when there is not enough to eat: eating behaviors and perceptions of food among food-insecure youths. Am J Public Health 99, 822-828. 